\title{
GAME CENTER: WAHANA PERMAINAN BERBASIS TRADISIONAL DAN DIGITAL
}

\author{
Sari Wahyuni ${ }^{1}$, M. Ridha Alhamdani², Jawas Dwijo Putro ${ }^{3}$ \\ ${ }^{1}$ Mahasiswa, Program Studi Arsitektur, Fakultas Teknik, Universitas Tanjungpura. \\ sari.thesmart@gmail.com \\ ${ }^{2}$ Program Studi Arsitektur, Fakultas Teknik, Universitas Tanjungpura \\ ${ }^{3}$ Program Studi Arsitektur, Fakultas Teknik, Universitas Tanjungpura
}

Naskah diajukan pada: 21 Desember 2020

Naskah revisi akhir diterima pada: 23 Desember 2020

\begin{abstract}
Abstrak
Seiring berjalannya waktu, setiap orang tumbuh besar dengan apa yang ia mainkan seumur hidupnya. Hal ini berdampak pada minat para pemain baik tua maupun muda yang akan semakin bertambah tiap tahunnya. Saat ini Pontianak belum memiliki pusat permainan tersebut. Sedangkan peminat permainan terutama dari segi audio visual semakin tinggi. Dari data statik di Statista menyebutkan tingginya permintaan serta aktivitas dari permainan. Oleh karena itu, perlu dilakukan perancangan Game Center. Perancangan Game Center ini dirancang tidak hanya sebagai fungsi pusat permainan semata tetapi juga berfungsi sebagai tempat permainan-permainan tradisional masyarakat lokal serta sebagai ruang komunal yang menampung aktivitas sosial. Perancangan pusat permainan ini dilakukan dengan menganalisis internal dan eksternal dari sumber dan literatur serta standar acuan dalam merancang pusat permainan yang ada. Kebutuhan ruang dari kegiatan pelaku juga perlu dianalisis untuk menemukan program ruang di dalam pusat permainan. Fungsi, tata ruang, sirkulasi maupun utilitas sangat diutamakan untuk menghasilkan Game Center dengan fungsi komunal. Bangunan dirancang dengan memiliki tiga masa bangunan yang terpisah. Satu masa bangunan diletakkan di bagian tengah sebagai bangunan utama dengan fungsi pusat. Kedua masa bangunan lainnya di letakkan mengitari bangunan utama.
\end{abstract}

Kata-kata Kunci: Permainan, Game Center, Komunal

\begin{abstract}
Abstrack
Over time, everyone grows up with what he remembers during our lifetime. Game Center is the place for the memory gathering. This has an impact on the interest of both young and old players which will continue to grow every year. Currently Pontianak does not have this game center. Meanwhile, game enthusiasts, especially in terms of audio-visual, are getting higher. From the static data in Statista, it states that the high demand and activity from games. Therefore, it is necessary to design a Game Center. The Game Center design is designed not only as a mere function of a game center, but also as a place for traditional games of the local community as well as a communal space that fills social activities. This game center design is done by analyzing internal and external sources and literature as well as standard references in existing game centers. The space requirements of the actors' activities also need to be analyzed to find the spatial program in the game center. Function, layout, circulation and utility are prioritized to produce a Game Center with communal functions. The building is designed to have three separate building masses. One mass building in the middle as the main building with a central function. The other two masses of the building are placed around the main building.
\end{abstract}

Keywords: Games, Game Center, Comunal

\section{Pendahuluan}

Industri permainan merupakan sebuah industri yang sedang berkembang dengan pesat, merupakan perpaduan antara perkembangan teknologi hiburan dan seni yang digemari oleh masyarakat luas. Bahkan di negara-negara maju, perkembangan teknologi dalam industri permainan seringkali menjadi salah satu kekuatan ekonomi yang utama, semisal di Jepang dan Amerika Serikat. 
Seiring dengan berkembangnya ilmu pengetahuan dan teknologi serta informasi, dunia game elektronik saat ini menjadi sektor hiburan yang bertumbuh paling cepat di dunia. Pada awal tahun 2000-an istilah Esport muncul dan menjadi sebuah topik ternama hampir diseluruh penjuru benua Eropa maupun Amerika. Istilah Esport sendiri belum memiliki pengertian atau definisi khusus. Huruf "E" berasal dari kata "electronic" yang berarti segala sesuatu yang menggunakan perangkat listrik dalam operasi sistemnya, dan "sport" yang berarti sebuah istilah untuk kegiatan fisik atau olahraga. Awalnya Esport berupa kompetisi yang hanya diselenggarakan oleh negara-negara maju di Benua Amerika dan Eropa. Namun, dengan semakin berkembangnya teknologi komputer dan video game, pertandingan Esport juga semakin marak dijumpai di negara-negara berkembang khususnya Indonesia. Sayangnya di Kalimantan Barat, khususnya Pontianak belum menyediakan fasilitas untuk permainan-permainan tersebut. Oleh sebab itu, diperlukan wadah yang dapat menunjang pengadaan khusus Esport di Pontianak, dengan fitur yang dapat dinikmati tak hanya pemain profesional, namun juga menjadi sarana hiburan bersama.

\section{Kajian Pustaka}

Menurut Kamus Besar Bahasa Indonesia (2016), permainan mempunyai banyak makna, namun dalam desain ini, makna permainan ditekankan pada sesuatu yang digunakan untuk bermain; barang atau sesuatu yang dipermainkan; mainan. Sedangkan menurut merriam-webster.com (2019), permainan adalah kompetisi fisik atau mental dilakukan sesuai aturan dengan peserta yang bertentangan langsung satu sama lain; divisi dari kontes yang lebih besar; cara bermain dalam sebuah kontes; aktivitas yang dilakukan untuk pengalihan atau hiburan. Dari penjelasan diatas dapat disimpulkan bahwa permainan merupakan sesuatu yang dimainkan seseorang agar mendapatkan suatu kesenangan darinya. Kata permainan memiliki definisi sesuatu yang digunakan untuk bermain; barang atau sesuatu yang dipermainkan. Kata tradisional memiliki definisi sikap dan cara berpikir serta bertindak yang selalu berpegang teguh pada norma dan adat kebiasaan yang ada secara turun temurun. Permainan tradisional maka memiliki makna sebagai sesuatu yang digunakan untuk bermain, yang berdasar pada cara berpikir dan bertindak yang berpegang teguh pada norma dan adat kebiasaan yang ada secara turun temurun. Bermain bagi anak merupakan kegiatan yang menyenangkan. bermain dapat mengembangkan berbagai potensi anak, tidak hanya pada potensi fisik saja, tetapi juga pada kognitif, bahasa, sosial, emosional, kreatifitas, dan pada akhirnya potensi akademik anak. bermain ada nilainya, yaitu bermain dapat mengembangkan keterampilan sosial, emosional, dan kognitif. Memainkan video game tiga dimensi selain menyenangkan dapat meningkatkan pembentukan ingatan. Penelitian tersebut menunjukkan bahwa game-game ini dapat meningkatkan koordinasi mata dan tangan serta waktu reaksi, temuan ini menunjukkan potensi pendekatan virtual baru untuk membantu orang-orang yang kehilangan ingatan seiring bertambahnya usia atau menderita demensia. Hasil studi muncul 9 Desember di The Journal of Neuroscience. Penelitian sebelumnya menunjukkan bahwa game meningkatkan keterampilan visual lainnya, seperti kemampuan untuk melacak beberapa objek pada waktu yang sama dan memperhatikan serangkaian peristiwa yang bergerak cepat, menurut Bavelier (2015).

\section{Metode}

Metode pengamatan dan pengumpulan data Pontianak Esport Center. yang digunakan oleh penulis adalah: a) Melakukan pengamatan dan peninjauan secara langsung sebuah tempat terkait yang berhubungan dengan konsep dan proses perancangan Game Center, b) Mewawancarai hal yang berkaitan dengan memperoleh data-data untuk mengetahui segala aktivitas dan sarana-sarana yang diperlukan dalam sebuah Game Center. Data yang sudah dikaji dan disusun dalam proyek tugas akhir dalam perancangan bangunan Game Center, yang disusun berdasarkan latar belakang, permasalahan, rumusan masalah, tujuan, sasaran, manfaat, lingkup, metode dan tinjauan pustaka dari judul yang ada dengan memperhatikan tata ruang dalam dan luar serta memberikan keleluasaan pada ruang dalam segala fasilitas yang diberikan. 


\section{Hasil dan Pembahasan}

Landasan konseptual mencakup pengelolaan data atau analisis untuk menghasilkan konsep perencanaan dan perancangan Game Center. Analisis data dilakukan sesuai metode pengolahan data meliputi analisis fungsi, analisis perlaku, analisis ruang, analisis lokasi perancangan, analisis tapak, analisis bentuk, analisis struktur, analisis utilitas. Analisis fungsi mengenai tahap identifikasi fungsi yang terkait perancangan Game Center, akan memiliki fungsi sebagai arena bermain serta lahan edukasi bagi penggunanya. Bangunan Game Center akan diutamakan sebagai Arena bermain, kanakkanak maupun dewasa. Game Center ini nantinya juga dibangun sebagai pusat edukasi, agar pemain serta pengunjung tak hanya sekedar mengunjungi pameran dan bermain, tapi juga agar mendapat wawasan di dalamnya. Tidak hanya berfungsi sebagai tempat bermain saja melainkan juga berfungsi sebagai tempat pewirausaha menggelar usaha mereka, terutama menyangkut permainan. Fungsi ini hanya sebagai fungsi pendukung pada bangunan yang menyediakan fasilitas ruang pelatihan dan ruang untuk menjual hasil karya.

\section{Landasan Konseptual}

Analisis internal dilakukan untuk menemukan ruang-ruang yang diperlukan pada perancangan Game Center. Cara yang dilakukan dalam menganalisis adalah dengan menggunakan analisis pelaku, analisis kebutuhan ruang, analisis persyaratan ruang, analisis hubungan ruang dan analisis besaran ruang. setiap analisis saling berkaitan dan saling mempengaruhi satu sama lain. Analisis pelaku di dalam Game Center yang akan dirancang terdapat empat pelaku yang terkait. Adapun pelaku tersebut adalah pengelola dari pihak Game Center yaitu pengelola, pengurus, pemain, serta pengunjung. Untuk analisis kebutuhan ruang dilakukan setelah menentukan pelaku yang menghuni di Game Center yang akan dirancang. Analisis tersebut dilakukan berdasarkan pada kegiatan sehari-hari pelaku di dalam pusat komunal untuk menentukan ruang-ruang yang dibutuhkan oleh pelaku tersebut. Adapun analisis kebutuhan ruang yang dilakukan adalah menganalisis kebutuhan ruang pengelola, anlisis kebutuhan ruang pengurus, analisis kebutuhan ruang pelaku dan analisis kebutuhan ruang pengunjung. Menganalisis persyaratan ruang, hal yang harus diketahui adalah mengelompokkan ruang-ruang yang telah diketahui dalam menganalisis kebutuhan ruang diatas. Pengelompokkan ruang dilakukan untuk mengetahui penzoningan serta sifat ruang pada Game Center. Selain itu analisis persyaratan ruang dilakukan untuk mengetahui analisis pencahayaan, penghawaan serta akustika pada bangunan yang akan dirancang. Analisis hubungan ruang, dilakukan untuk menemukan ruang-ruang apa saja yang saling berhubung atau tidak di dalam Game Center yang akan dirancang. Dalam menganalisis ini terdapat tiga jenis hubungan ruang yang dilakukan yaitu hubungan ruang langsung, hubungan ruang tidak langsung dan hubungan ruang yang tidak berhubungan dengan ruang lainnya. Analisis kebutuhan ruang pada Game Center, dilakukan untuk mengetahui luasan ruang-ruang pada yang akan dirancang. Luasan ruang-ruang tersebut dihitung berdasarkan standar yang ada diantaranya Asumsi Penulis dan Neufert (2001). Analisis besaran ruang juga akan mempengaruhi bentuk dan masa bangunan yang akan dirancang. Analisis eksternal dalam perancangan Game Center meliputi analisis tapak, struktur, utilitas hingga arsitektur lingkungan pada lokasi site. Untuk analisis tapak terdiri dari analisis perletakan, sirkulasi, orientasi, vegetasi dan zonasi. Setelah itu melakukan analisis gubahan bentuk untuk menentukan bentuk bangunan Game Center pada lokasi site. Lokasi perancangan berada di pinggir jalan Ahmad Yani. Berdasarkan RTRW Kota Pontianak Tahun 2013-2033, lokasi perancangan merupakan peruntukan lahannya adalah pemukiman yang sesuai dengan jenis bangunan Game Center yang akan dirancang yaitu hunian. Luas lahan perancangan adalah $\pm 63000 \mathrm{M} 2$ dihitung sesuai dengan analisis besaran ruang. Garis Sempadan Bangunan (GSB) pada Jalan Ahmad Yani adalah 23 meter dihitung dari As Jalan. Lokasi perancangan juga memiliki peraturan Koefisien Dasar Bangunan (KDB) sebesar 80\%, Koefisien Lantai Bangunan (KLB) 3,2 dan Koefisien Dasar Hijau (KDH) sebesar 30\%.

Analisis tapak terdiri dari beberapa tahapan analisis yang berhubungan dengan bangunan yang akan dirancang. Adapun analisis tapak yang diperlukan adalah analisis perletakan, analisis sirkulasi, analisis oriantasi, analisis vegetasi dan analisis penzoningan. Analisis ini merupakan tahapan analisis 
tapak yang pertama di lakukan karena analisis ini sanagat mempengaruhi perletakan bangunan Game Center yang akan dirancang. Pada analisis perletakan terlihat bahwa bagaimana posisi bangunan pada site dengan pertimbangan peraturan yang berlaku terhadap site seperti GSB yang memotong site sehingga posisi bangunan tidak mendekati jalan yang ada pada site. Analisis perletakan dimulai dari pehitungan GSB pada jalan Ahmad Yani kemudian menganalisis jalur yang ada pada site sehingga bangunan tidak langsung diletakkan di pinggir jalur tersebut karena pertimbangan terjadinya kebisingan dari jalur tersebut. Selanjutnya adalah menganalisis disisi barat dan utara site yang harus diberikan jarak untuk sirkulasi udara dan akses terhadap utilitas bangunan. Tahap selanjutnya setelah perletakan adalah menentukan orientasi bangunan pada tapak. Perlunya melakukan analisis tapak orientasi bangunan adalah untuk menemukan entrance utama bangunan yang akan dibuat dengan melakukan analisis arah mata angin, sinar matahari serta kebisingan yang terjadi di sekitar site. Analisis pertama yang dilakukan menganalisis arah mata angin dan pergerakan sinar matahari karena untuk menentukan area ruang privat seperti kamar tidur yang harus terkena sinar matahari pagi. Selanjutnya menganalisis view dari lokasi maupun ke lokasi agar bukaan ruang tidak terhalau oleh bangunan disampingnya. Kebisingan harus dihindari dari ruang privat lainnya serta sinar matahari sore juga harus dihindari dari ruang privat. Selanjutnya bangunan utama yang terdapat fungsi retail harus berorientasi ke jalan utama untuk menarik perhatian pengunjung. Tahap analisis sirkulasi adalah bertujuan untuk menentukan akses sirkulasi masuk maupun keluar pada site. Analisis sirkulasi ini dilakukan berdasarkan aspek yang mempengaruhi akses sirkulasi ke tapak, seperti akses dari jalan utama maupun arus kendaraan yang lewat. Analisis sirkulasi dilakukan dengan cara memberi simbol garis berwarna. Panah berwarna hitam adalah jalur sirkulasi ke bangunan. Berdasarkan analisis diatas didapatkan jalur sirkulasi utama ke bangunan yaitu dari Jl. Ahmad Yani. Jalur ini dipilih agar dapat mengurangi arus lalu lintas yang terjadi di jalan utama, sehingga arus kendaraan dari bangunan dapat diminimalisir. Analisis vegetasi diperlukan untuk memperindah bangunan ataupun kawasan pada site perancangan. Selain itu analisis vegetasi di lakukan untuk meredam kebisingan dan menghalau paparan sinar matahari sore ke dalam bangunan. Kesan adanya pemberian berupa vegetasi adalah agar suasana pada site lebih hijau dan terasa sejuk. Analisis pertama dalam analisis vegetasi ini adalah memipertimbangkan beberapa vegetasi yang telah ada pada site seperti di sebalah barat site dipertahankan untuk meredam kebisingan, serta sinar sore. Untuk bagian utara site diberi vegetasi yang rendah untuk menutupi area pojokan jalan. Selain itu pada sisi timur dan selatan site diberi vegetasi berupa tanaman hias dan tumbuhan pucuk merah agar view ke parkiran dari jalan utama tidak langsung terlihat oleh pengendara serta dapat meredam kebisingan dari jalan di selatan.

\section{Hasil Perancangan}

Hasil perancangan setelah melalui tahapan analisis konseptual yang telah dilakukan sebelumnya. Kemudian diwujudkan dalam rencana nyata berupa gambar kerja yang diperlukan sebagai acuan perancangan Game Center. Adapun isi bagian ini adalah berupa gambar site plan, denah, tampak dan visualisasi suasana interior maupun eksterior bangunan yang dirancang. 
Site plan merupakan gambar kerja yang berisikan denah bangunan perancangan Game Center yang dilengkapi dengan layout tempat parkir, jalur sirkulasi, serta vegetasi disekitar bangunan. Site plan dilengkapi dengan notasi luas lahan pada site perancangan agar serta dilengkapi dengan arah mata angin untuk mengetahui posisi site perancangan.

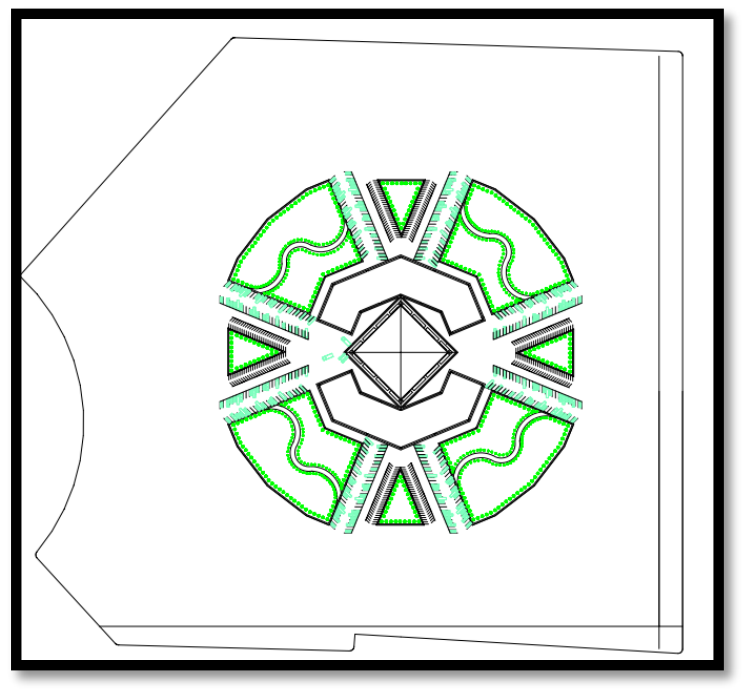

Gambar 1. Site Plan

Sumber: Analisis Penulis, 2020

Bangunan memiliki tiga masa bangunan yaitu bangunan utama, bangunan museum digital dan bangunan museum tradisional. Untuk bangunan komunal/utama memiliki jumlah 3 lantai dengan fungsi komersil dan penunjang. Untuk lantai dasar bangunan komunal terdapat cafe, elektronik, ruang pengelola, gudang, wc, dan lobby.

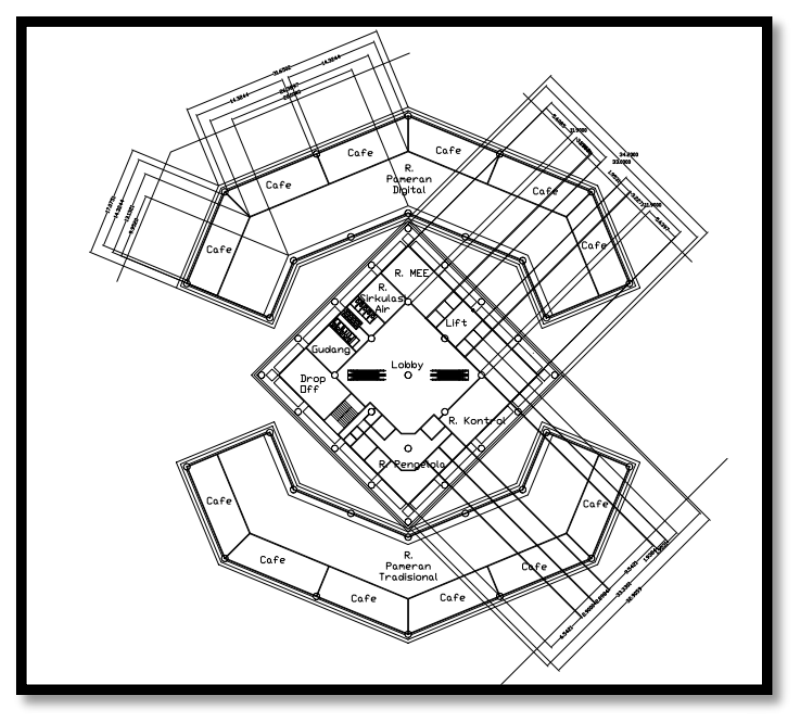

Gambar 2. Denah Lantai 1

Sumber: Analisis Penulis, 2020

Selanjutnya pada denah lantai 2 bangunan komunal depan, berisi ruang seperti aula, kantin, ruang persiapan. Lantai 2 ini juga dilengkapi dengan wc dan lobby aula. 


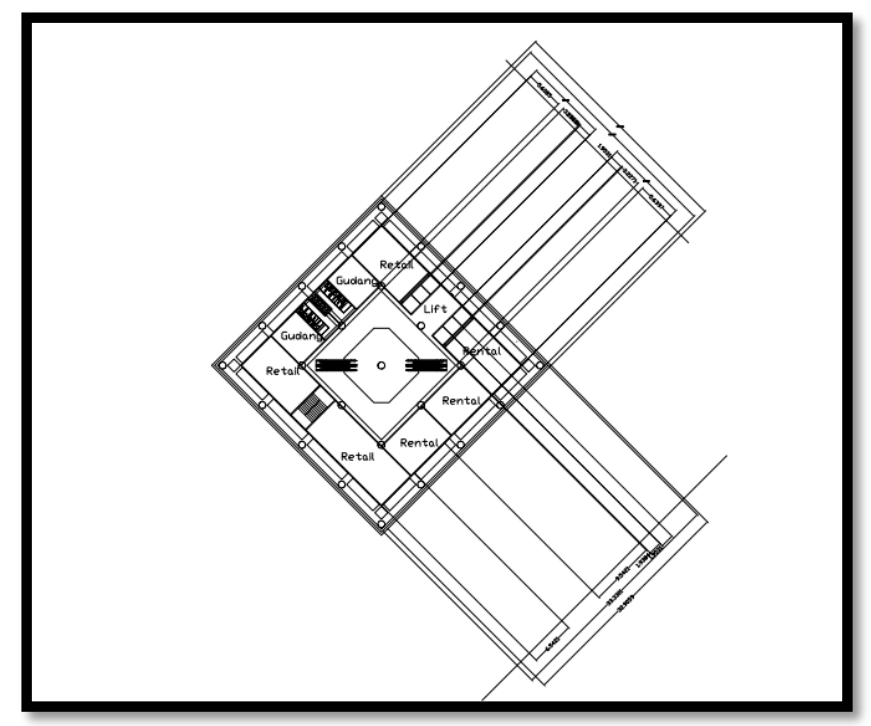

Gambar 3. Denah lantai 2

Sumber: Analisis Penulis, 2020

Lantai 3 bangunan terdapat ruang komunal untuk arena permainan, termasuk perlombaan. Perencanaan ruang-ruang dibuat khusus dengan penyebaran suara yang baik.

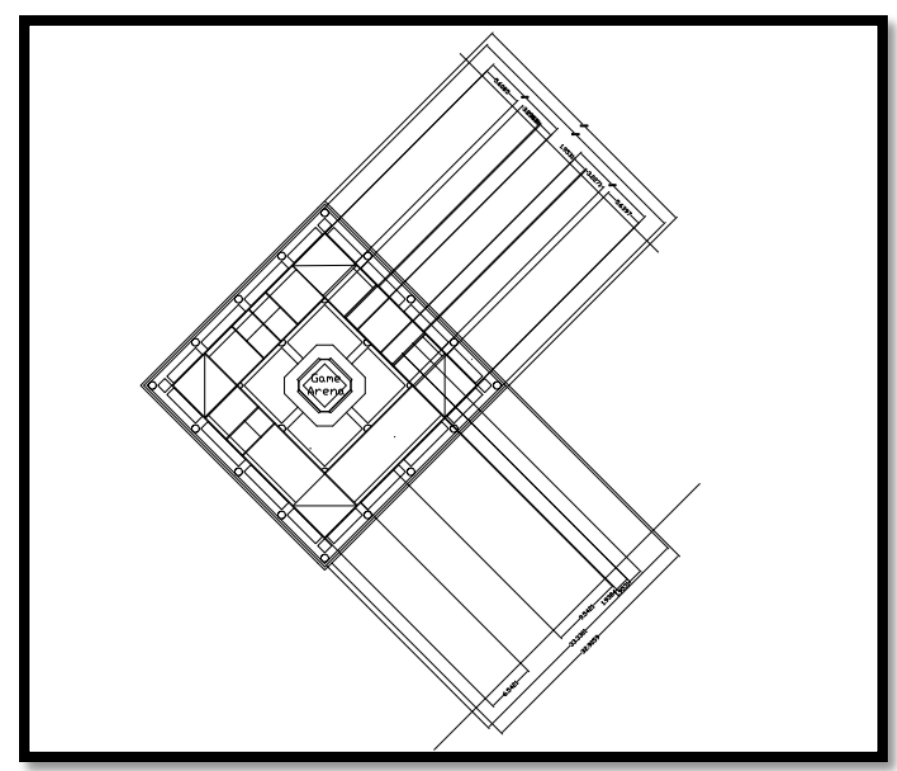

Gambar 4. Denah lantai 3

Sumber: Analisis Penulis, 2020 
Tampak merupakan gambar kerja selanjutnya yang dirancang terkhusus untuk bangunan Game Center yang menjelaskan gambaran ke-empat sisi bangunan dengan arah pandang yang berbeda. Adapun arah pandang mata manusia ke bangunan atau pun ke dalam site perancangan bangunan dilihat dari sisi depan, samping kanan, samping kiri, dan sisi belakang.

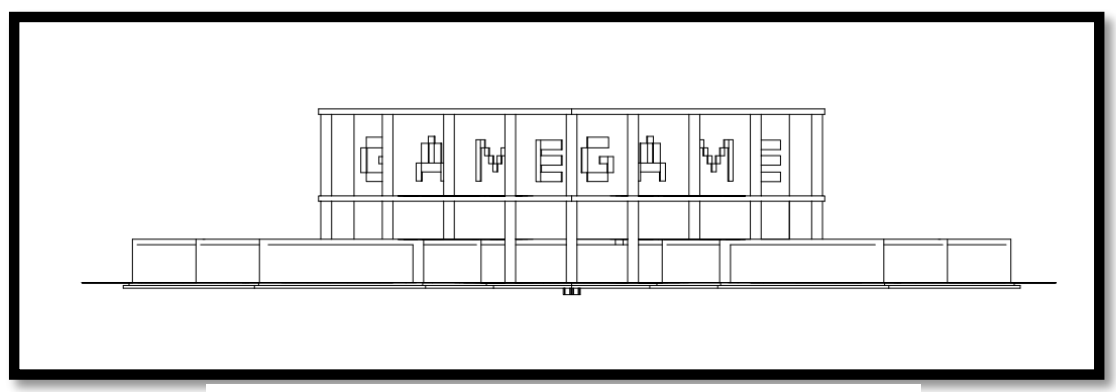

Gambar 6. Tampak Kiri dan Kanan

Sumber: Analisis Penulis, 2020

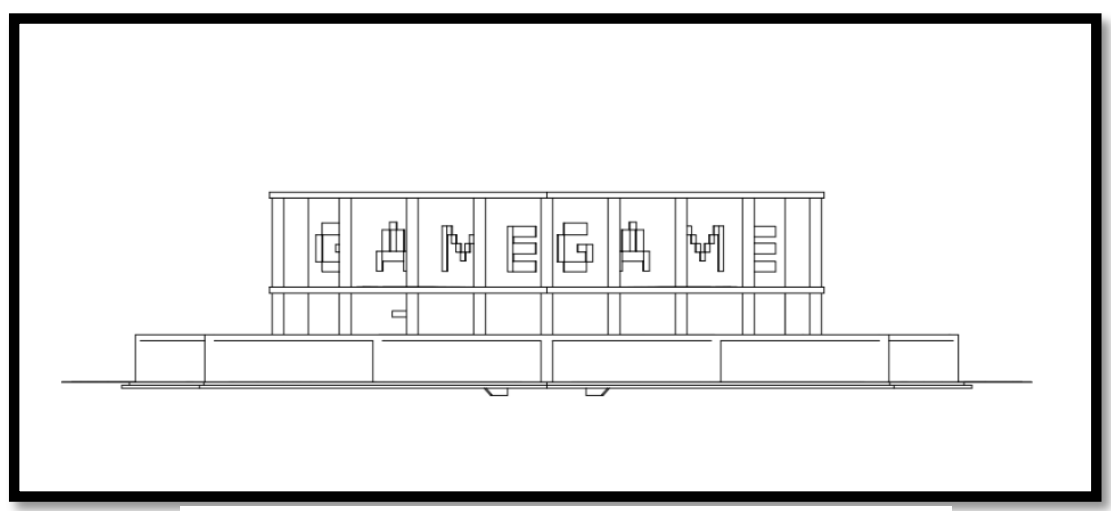

Gambar 5. Tampak Depan dan Belakang

Sumber: Analisis Penulis, 2020

Tahap selanjutnya adalah hasil akhir dari desain perancangan bangunan yang berupa gambar visualisasi 3D dari komputer yang mengacu pada gambar kerja teknik yang telah dibuat sebelumnya. Gambar visualisasi 3D ini dibuat untuk menggambarkan suasana yang ril dari perancangan bangunan baik dari dalam bangunan maupun luar bangunan.

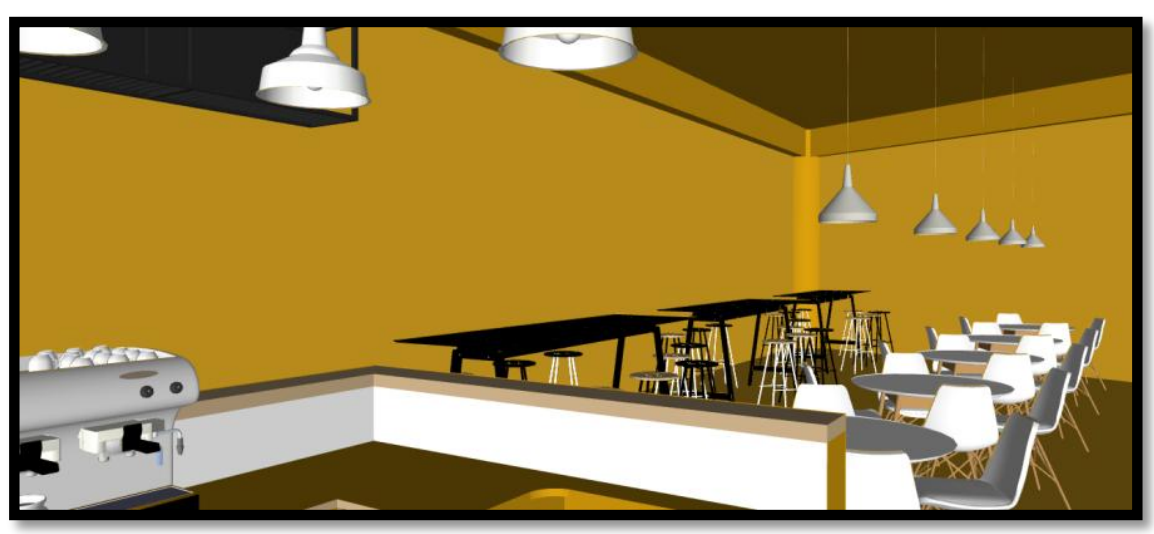

Gambar 7. Interior Cafe

Sumber: Analisis Penulis, 2020 


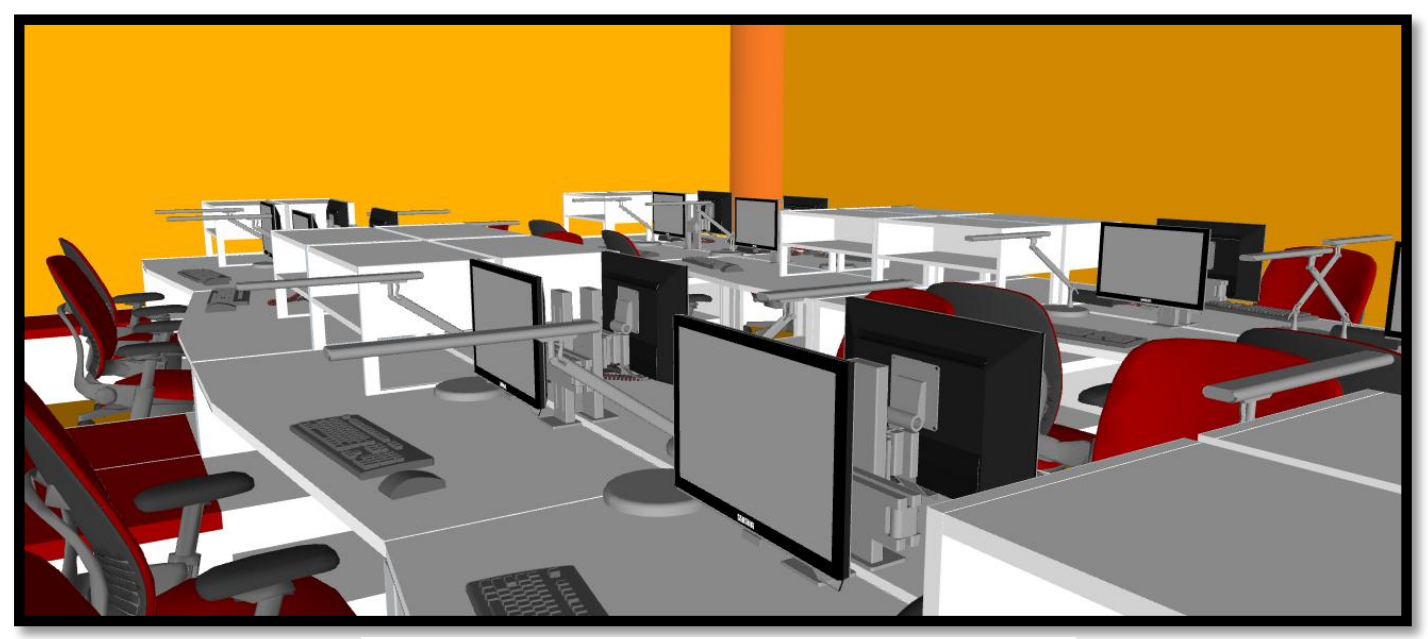

Gambar 8. Interior Rental

Sumber: Analisis Penulis, 2020

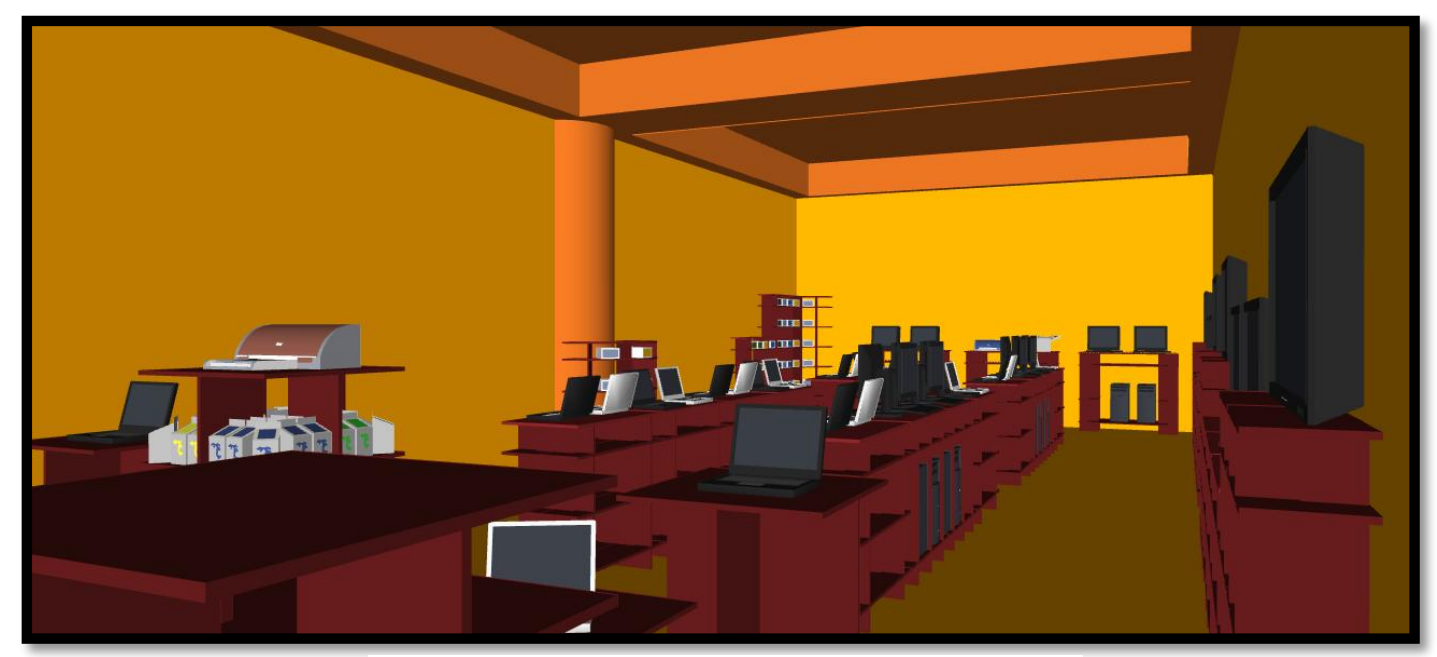

Gambar 9. Interior Retail

Sumber: Analisis Penulis, 2020

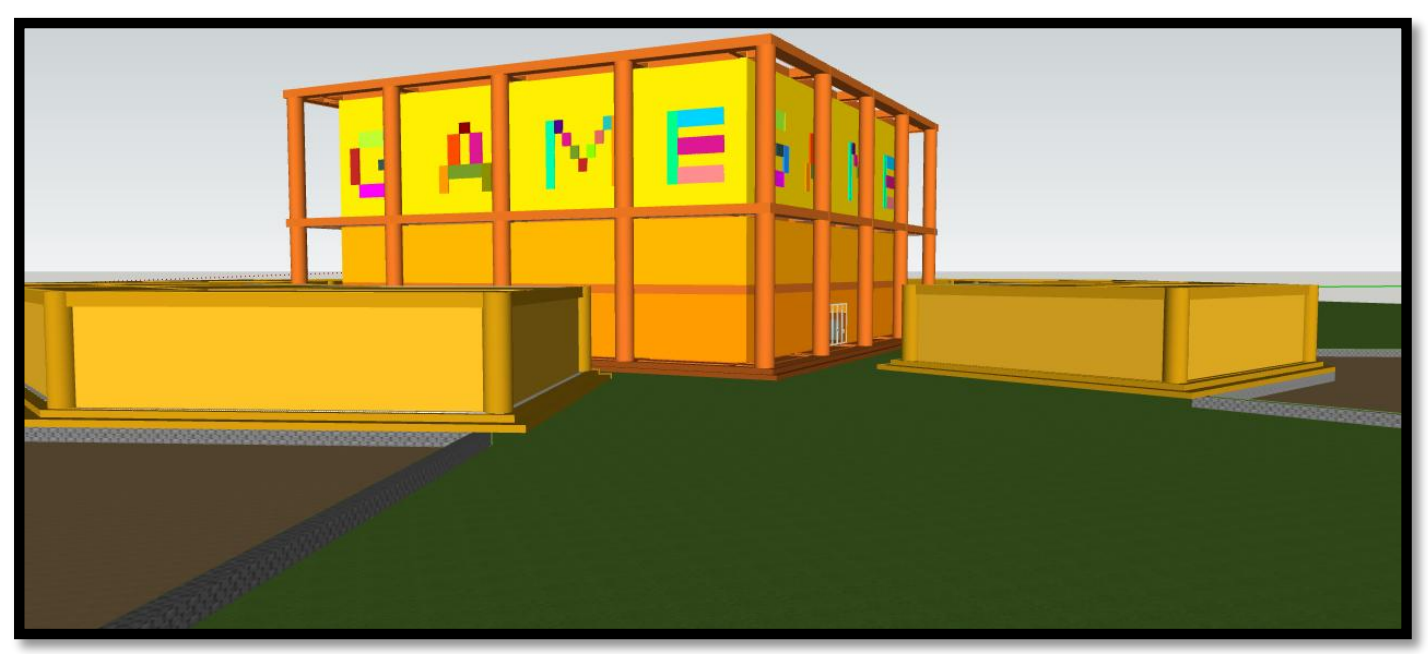

Gambar 10. Suasana Eksterior

Sumber: Analisis Penulis, 2020 


\section{Kesimpulan}

Game Center menjadi wadah untuk memamerkan, memproduksi, dan sekaligus memasarkan produk permainan nasional maupun internasional. Menciptakan lingkungan yang mempresentasikan nilai estetika dan harmonisasi budaya lokal terhadap modernisasi. Melalui prinsip arsitektur kontemporer sebagai pendekatan arsitektur yang mendukung penciptaan ruang-ruang yang memiliki suasana inovatif, kreatif dan menyenangkan. Memberikan paket wisata berupa sentra dalam wujud fasilitas bersama yang mengangkat fungsi komersil, rekreasi, pertunjukan dan edukasi. Sehingga Game Center dapat menciptakan lingkungan wisata unggulan di Kota Pontianak maupun di Provinsi Kalimantan Barat.

\section{Ucapan Terima Kasih}

Terima kasih atas karunia yang telah Allah SWT berikan kepada penulis, sehingga dapat menyelesaikan Proyek Tugas Akhir ini. Terima kasih juga kepada kedua orang tua saya Ibu dan Bapak keluarga besar, serta kerabat dan dosen yang selalu memberikan doa, dukungan dan semangat. Selalu berusaha dan jangan takut untuk melangkah dalam menggapai cita-cita.

\section{Daftar Acuan}

Bavelier. (2015). The Journal of Neurosience. Retrieved from https://www.jneurosci.org/content/31/3/992.short

Kamus Besar Bahasa Indonesia. (2016). "Permainan". Retrieved from https://kbbi.kemdikbud.go.id/entri/permainan

Merriam-Webster. (2020). Merriam-Webster.com Dictionary. "Game". Retrieved from https://www.merriamwebster.com/dictionary/game

Neufert, P.E. (2001). Data Arsitek Jilid 1. Jakarta: Erlangga

Pemerintah Daerah Kota Pontianak. (2013). Peraturan Daerah Kota Pontianak tentang Rencana Tata Ruang Wilayah Kota Pontianak 2013-2033 No.02. Pontianak: Pemerintah Daerah Kota Pontianak 